\title{
On Intercultural Infiltration Teaching Methods in Foreign Language Teaching in Colleges and Universities
}

\author{
Yun Li \\ Xi'an University School of Foreign Studies,Xi'an, China 710065
}

Keyword: Foreign Language; Intercultural Infiltration; Teaching Methods

\begin{abstract}
In order to continue to implement quality education of English teaching in colleges and universities, enable students better grasp the language skills and improve the ability of language application to overcome obstacles of communication and improve their overall language quality through language learning, this paper mainly discusses the requirements of intercultural communication in English and the relationship between language and culture from cultural quality education. Besides, this paper also puts forward the application of intercultural infiltration in college English teaching methods.
\end{abstract}

\section{Introduction}

In the process of English teaching in colleges and universities, in order to improve students' thinking style and language ability, cultivate healthy personality and enhance cultural awareness, it is necessary to carry out quality education for students so that students can fully understand the international differences between China and other countries, achieve cross-border literary exchanges and enhance global awareness. Quality education in English mainly includes language knowledge, basic skills of listening, speaking, reading and writing as well as English social skills. In the process of cultivating social skills, teachers must handle the dual relationship between language and culture, respect the cultural differences between China and foreign countries and fundamentally improve the language quality and understanding ability. In the national curriculum standards, there is a detailed description of cultural awareness and language has a rich cultural connotation. In the process of foreign language teaching, it is necessary to have a comprehensive understanding and study other aspects of the national culture, such as geographical knowledge, local customs and practices, traditional customs and lifestyles, which are conducive to the understanding and study of foreign languages, enhance understanding of the national culture and foster awareness of world and globalization.

\section{Relationship between Language and Culture}

As a composite carrier, language carries the knowledge and belief, ethics, customs and lifestyle of a country as well as local customs and practices, which has a direct impact on the learning ability and thinking habit of members of society. Language as a carrier of culture can let students have a comprehensive understanding of foreign cultures and development through learning a foreign language. In international cultural exchanges, we should respect differences, understand individualities and seek cooperation and development through mutual respect. As a true portrayal of culture, language profoundly reflects the basic form of culture, which directly affects people's perception of the world. Because language and culture are indivisible, people are accustomed to using language to evaluate the existence of objective things. The use of language has a direct impact on the construction of the cultural system. In order to better grasp the development and context of culture, we must accurately grasp the use of language, reduce cross-cultural barriers between cultures and make international exchanges well-deserved. By improving the ability of using the language, we can understand the cultural differences of different countries in a real sense. In the process of learning, students have various obstacles because of the difference of language use and thinking culture, which will cause obstacles in communication, inaccurate language and even serious mistakes, affecting the friendship and development among countries. 


\section{The Necessity of Strengthening Intercultural Teaching}

Cultural Differences Create Difficulties in Communication. In the current university English teaching process, many teachers can not understand and recognize the importance of intercultural teaching. Learning language is not only through the accumulation of common sense and habits, but also needs to solve the problems in time. The phenomenon of coupling exists in culture, such as long hair and short wit in English, which is basically the same as it in Chinese. However, each cultural common sense takes the important influence of the cultural background and has great differences due to the different cultural backgrounds. For example, better be the head of dog than the tail of a lion in English. If according to Chinese common sense to understand, this sentence means that it is rather to do chicken head than do the pheasant tail. This kind of metaphorical method has an essential difference between Chinese and Western cultures. Some Chinese proverbs come from the allusions of traditional culture, while some of the proverbs in English come from Greek mythology. In intercultural communication, in order to enhance students' abilities of listening, speaking, reading and writing, it is necessary to carry out targeted cultural background and cultural differences in the popularity of knowledge according to different modes of expression, cultural background and communicative means of different communicative objects. If there is a language error in the cultural exchanges, it is easy to be misunderstood by the other party, resulting in the failure of the transaction or even cultural conflicts. Therefore, it is necessary to improve the ability of using the language, achieve intercultural communication and enhance the overall abilities of the students' languages.

Cultural Awareness Is the Key to Language Learning. In the process of language learning, it is necessary to let students have a profound understanding of the cultural patterns and cultural norms of the language environment. If students do not grasp these two points in detail, they will not be able to achieve true language learning. Due to the lack of cultural background knowledge, language has produced many mistakes in its use. The purpose of language existence is to convey the specific cultural background of our nation. Without understanding the purpose of language existence, it is difficult for us to understand the meaning of many words used in language. In the process of teaching Chinese and English, people have different views on certain commonly used terms due to the difference between Chinese and Western historical and cultural beliefs and customs. For example, the Chinese translation of "the foremost dog catches the hare" is that early bird gets the worm. However, the birds eat insects correspond to dogs and rabbits. Chinese students can hardly imagine with Chinese thinking. For example, the dragon is a sacred symbol in Chinese traditional culture and is a totem of Chinese civilization. Besides, Chinese people like to say that they are dragon descendants. However, in the West's Bible, the dragon is a symbol of evil. Therefore, in the whole process of cultural exchange, there have been many misunderstandings about the dragon. Foreigners are fond of animals such as cats, dogs, rats and other animals. "the lucky dog, you are a gay dog" can be found in their culture, which shows their compliments to dogs. For Chinese people, cultural accumulation will make it hard to accept. There are many traditional Chinese words like Westerners metaphor, such as gou zhang ren shi, zei mei shu yan. These words are derogatory term and the exchange of Western culture has made a big difference. There are other words, such as blue picture and green hand. These words, if understood in Chinese, are blue pictures and green hands. However, they are actually yellow movies and inexperienced people. If only through our own position to understand the differences between Chinese and Western cultures, I am afraid that these words will never be understood.

The Key to Accomplish the Education Goal. In the process of college English teaching, it is necessary to develop students' communicative competence, which is one of the important goals of language teaching. Communicative competence is based on language ability, while students with language ability do not necessarily have communicative competence. Many people think that communicative competence includes the ability of listening and speaking, reading and writing, social ability and proper intercourse with people from different cultural backgrounds. Therefore, we must attach importance to the combination of language ability and the ability to use and the actual life, so that the language and cultural competence constitutes an important aspect of the communicative competence of students, achieving the goal of language teaching. 


\section{Principles and Measures of Intercultural Teaching in Foreign Language Teaching}

Principles. First, the principle is from shallow to deep. College students' English learning is layered and phased. With the continuous improvement of cognitive ability, the content of cultural learning needs step by step from shallow to deep. In the initial stage of learning, cultivate students' cultural awareness, guide students to ask questions about the cultural that they do not understand and avoid the mistakes of language usage. In the initial stage of English learning, teachers should take the initiative to introduce daily communication and cultural factors, such as the use of some spoken language and the meaning of proverbs in different contexts. For example, the Chinese translation of "when in Rome, do as Romans do" is that when you are in Rome, do as the Romans did. In fact, a simple translation is to follow the custom. Through students' understanding of foreign political, economic and cultural backgrounds, students should pay more attention to the differences between communicative and cultural aspects and pay more attention to the difference of knowledge and culture at the initial stage.

The second is the principle of suitability. During the teaching process, teachers need to design and explain the cultural differences that are closely related to the language to be learned according to the content and quantity of students' learning at different stages, so that the language consistency is continuously improved. In the basic stage of learning, students should skillfully master the differences between languages. As teaching language is not equivalent to understanding and imitation of Chinese, teachers must enable students to profoundly understand the meaning of cultural differences. In the early teaching stage, the content of a lesson should not be too much and it can not affect the teaching of basic knowledge.

Teaching Methods of Intercultural Awareness Permeation. Basic knowledge level teaching method. As students focus on the practice of test in high school, they do not have a strong understanding of the practicability of English and lack a comprehensive understanding of cultural differences. Therefore, in the process of college English learning, it is necessary to start from the foundation and comprehensively elaborate the relationship between Chinese and Western culture. In the introductory stage of the teaching process, due to the limited number of students' mastery of knowledge and the narrow scope of knowledge involved, the contents and topics of learning are closely related to daily life. Therefore, in conversation, we need to expand the study of grammar and vocabulary knowledge, conduct cultural introduction and use everyday language as the mainstay, including titles, presentations, farewell, congratulations, and economics and so on. Two different ways of thinking to express different cultural differences in the teaching process call from the initial language communication call, therefore, the appropriate call directly affect the communication effect. There are not many differences between China and the West in terms of calling family members and relatives, but the names of the elders in China and the West are different. Some people call their parents or grandparents names directly at abroad. Some intimate terms are common in the daily communication between Europe and the United States, such as love, honey, etc. However, in China, these expressions are not so obvious. There is a big difference between Chinese implicitness and Westerners. In formal and informal occasions, the expression of love is not obvious, which is an important difference between Chinese and Western cultures. For the differences between these appellations, in the early stages of teaching, teachers should carry on the knowledge infiltration to the students gradually from the initial family members to the colleagues to the social interpersonal relationships and strangers.

Teachers should understand the differences between Chinese and Western cultures and enhance their self-cultivation. Teachers need to have a comprehensive understanding of the cultural differences existing in China and the West, such as communication of behavior. In terms of greetings and farewell, the differences between east and west are quite obvious. When meeting, Chinese people often ask that have you bought things, have you eaten or how is your family. It seems to foreigners that this is a matter of personal privacy. They are unwilling to answer, or even very offensive. Therefore, people often say goodbye or see you tomorrow in English. Chinese in addition to goodbye, the host will say please be careful when you on road to home. Foreigners will feel very confused at this time. Therefore, the host needs to say thank you, goodbye and see you next time on these occasions, which is already very decent. This is a question that teachers must pay attention to in the process of teaching. In terms of courtesy and 
competition, Chinese traditional culture is rather subtle and modest, so modest expression is common. While, you must open it in person and say thanks to the host when you receive a gift in foreigners' contact. In service, we should pay attention to the use of occasions when we want to express thanks. We should use please, would or help when treat Westerners. Besides, we need to respect westerners' habits and avoid talking about sensitive topics. For example, personal age, weight, religious beliefs and private life, which are taboo in the process of Westerners interaction.

Phases of the presentation. Teachers can guide students' learning in stages and set different topics for teaching. For example, in the case of gifts, the Chinese tend to refuse or accept gifts unwillingly. Besides, they usually will not open the case in person if they accept the gifts. However, it is considered impolite to show off or to be modest in abroad. People should open the gift face to face and praise sincerely, which shows a person's basic qualities. In praise, people often use the praise and compliment as the introduction of conversation in the English and American society, which shows respect for individuals by complimenting other people's efforts on some outstanding aspect. For example, people often flatter others beautiful or obvious weight loss. In addition to the above aspects, Anglo-American people will make a series of compliments about what someone did, to win a match, to have a good meal, etc. People's attention is not simply about the technology or the work itself, but focusing on the results of the effort, which is obviously different from Chinese people.

As a unique art, language plays an important role in daily communication. In order to further improve students' language ability and expand their language and cultural knowledge, college English teaching must be based on the age characteristics of students and their cognitive abilities in different stages. Starting from the daily life, teachers should enable students to have a stronger sense of English and stimulate students' interest in learning. In the high-quality learning phase, students should be exposed to a large area of other cultures to enable them to broaden their horizons and scope, enhance their ability to distinguish ordinary cultures and improve their ability to communicate with other countries.

\section{Reference}

[1] X. L. Gu. Theory and Practice Model of Intercultural Communication Competence in Foreign Language Teaching [J]. Foreign Language World, 2017, (01): 79-88.

[2] J. L. Zhao. On the Penetration of "Native Culture" in Foreign Language Teaching in Colleges and Universities [J]. Knowledge and Economy, 2015, (13): 126.

[3] H. R. Yan. My View on Local Culture Infiltration in College Foreign Language Teaching [J]. Journal of Jiamusi Polytechnic University, 2015, (01): $135+137$.

[4] J. F. Wu. On Cultivation of Intercultural Awareness and Improvement of Intercultural Communication Competence in College English Teaching [J]. Jiangsu Foreign Language Teaching and Research, 2011, (01): 26-28.

[5] G. C. Duan. Cultural Infiltration Teaching in College English Teaching [J]. Modern Communications, 2011, (01): 28.

[6] C. Q. Yang. Strategies for Cultivating Cross-cultural Awareness in Foreign Language Teaching [J]. Journal of Heilongjiang College of Education, 2010, (05): 108-111. 